\title{
The Relation between Orthography and Phonology from Different Angles: Insights from Psycholinguistics and Second Language Acquisition ${ }^{1}$
}

\section{Ellen Simon', Mieke Van Herreweghe}

\author{
Ghent University, Belgium
}

Between phonological forms and their orthographic representations a close connection can be established. Previous psycholinguistic research has amply illustrated that word recognition can be influenced by orthography (Perre \& Ziegler, 2008; Taft, 2001) and that orthography plays a role in phonemic awareness (Cheung, Chen, Lai, Wong, \& Hills, 2001; Tyler \& Burnham, 2006). However, despite the long-standing acceptance of the importance of orthography in word recognition, little research has been carried out on how orthography may exert any influence on second language acquisition. The interest in orthography has so far mainly come from two fields: the field of psycholinguistics and that of reading acquisition.

In the field of psycholinguistics the focus of previous studies has often lain on the effects of spelling-to-sound inconsistencies and sound-to-spelling inconsistencies on word recognition (Pattamadilok, Morais, Ventura, \& Kolinsky, 2007; Ziegler \& Ferrand, 1998; Ziegler, Petrova, \& Ferrand, 2008). The aim is to get an insight into how exactly graphemes are mapped onto phonemes in the minds of literate people and into the extent to which there is feedback between the lexical and the phonological and orthographical components.

The onset of reading has been shown to have an effect on the child's developing phonological system (Goswami, Ziegler, \& Richardson, 2005). First language acquisition studies often aim at examining to what extent learning to read promotes phonemic awareness (or syllabic awareness, in some non-alphabetic languages) or to what extent this awareness assists children in the acquisition of their language's writing system

1 We wish to thank the Language and Speech Editors, Tim Bunnell and Irene Vogel, for their enthusiastic response to our initial proposal and for giving their support to this special issue. We also warmly thank the Editorial Manager, Jim Polikoff, for guiding us so efficiently through the editorial process. We are grateful to all authors for their contributions and to all reviewers for their excellent suggestions and comments.

2 This research has been made possible thanks to a postdoctoral fellowship from the Research Foundation-Flanders (FWO). 
(Nunes, Bryant, \& Olsson, 2003; Pan \& Chen, 2005). With respect to L2 reading and writing, the edited volume by Cook and Bassetti (2005) presents a collection of studies dealing with the question of how reading and writing in a second language are related to first and second language writing systems.

The implications of the connection between orthography and phonology for second language phonology have only recently been addressed by a number of researchers. For instance, Weber and Cutler (2004) suggest that orthographic knowledge may influence L2 spoken word processing. Evidence for this was presented by Escudero, Hayes-Harb, and Mitterer (2008), who showed that orthographic input during training on novel words influenced the word recognition pattern of the listeners.

In sum, the relationship between orthography and phonology or phonological acquisition is currently being approached by researchers from different subdisciplines of linguistics. With this special issue we want to bring together studies which look at this topic from different angles, to arrive at a broader picture and ultimately a deeper understanding of the intricate relation between phonology and orthography and what it can mean for first and second language acquisition.

The articles in this special issue explore how orthography and phonology are related to each other and what this means for cognitive domains such as word recognition and verbal working memory, or how the connection between orthography and phonology can bear upon issues of second language acquisition and first language orthographic processing. They analyze questions such as whether orthography is automatically triggered in spoken word recognition tasks, how orthographic input influences L2 perception and word recognition and how homophones may influence spelling acquisition. The studies are mostly experimental, but one study also includes a corpus-based approach. Finally, the studies do not only consider the effect of orthography on phonology, but they also deal with the effect of phonology on orthography.

The first two articles in the issue (i.e., by Cutler, Treiman, \& van Ooijen and by Pattamadilok, Lafontaine, Morais, \& Kolinsky) investigate the influence of orthography in the cognitive domain. Cutler, Treiman, and van Ooijen examined whether phoneme detection is sensitive to the orthographic realizations of target phonemes. Importantly, they found that listeners' response times in a phoneme detection task were influenced by whether the targets had consistent or inconsistent spellings only when spelling was rendered salient in the experiment, which was ensured by including a large number of irregularly spelled filler words. This entails that knowledge of spelling is not automatically available as word candidates are activated, but can be made available by an input which triggers listeners to become sensitive to the orthographic input. Since phoneme detection tasks are widely used in spoken word recognition research, the article has important methodological implications.

Pattamadilok, Lafontaine, Morais, and Kolinsky went a step further and explored whether orthography can have an effect not only on word recognition, but also on other cognitive domains, such as verbal working memory. They carried out a serial word recall experiment in which the seven items in a series differed in the extent to which they were orthographically dissimilar. They found that orthographic dissimilarity can assist verbal working memory by reducing or even avoiding the detrimental effect of phonological similarity that normally leads to worse serial recall performance 
with rhyming than with non-rhyming items. Since verbal working memory plays an important role in language acquisition, the relation between orthography and word recall has implications in that field as well.

The articles by Cutler et al. and Pattamadilok et al. are followed by three contributions on the effect of orthography on various aspects of non-native language acquisition.

Escudero and Wanrooij examined the effect of L1 orthography on non-native vowel perception by Spanish-speaking learners of Dutch. They conducted a set of sound labeling experiments in which listeners were presented with or without orthographic input. They showed that when listening to auditory stimuli only, native speakers of Spanish have great difficulty classifying certain Dutch vowels, regardless of the amount of experience they have with Dutch. At the same time these listeners were influenced by the orthographic labels presented to them. Remarkably, this influence could be positive or negative, depending on the specific vowel contrast and their orthographic representations in the L1 and the L2.

In Hayes-Harb, Nicol, and Barker's study, the potential effect of orthographic input on the representations of newly learnt (pseudo-)words was examined. Hayes-Harb et al. provided evidence for a relationship between orthographic and phonological representations of newly learnt words. They trained speakers on the meaning of a set of new pseudo-words in one of three conditions: with written forms that were or were not consistent with English spelling conventions and without written forms. During testing, only participants who were trained with the inconsistent spellings showed interference from spelling. Further research will need to show whether orthographic input can also help learners to build distinct phonological representations for new words (Simon, Chambless, \& Alves, 2010; Escudero \& Simon, in preparation).

The third article on L2 learning is by Ota, Hartsuiker, and Haywood. They report on three experiments in which native speakers of English, L1 Japanese learners of English and L1 Spanish learners of English perform a visual semantic categorization task. The aim of the experiments was to find out whether near-homophone effects could be found with native speakers of languages with the same writing system as English, in addition to native speakers of a language with a different writing system. The results revealed that homophones elicited more false positive errors in all three groups, and that near-homophones elicited more false positive errors in the Japanese-English group, but not in the Spanish-English group, suggesting that the near-homophone effect may be blocked when the L1 and the L2 share the same writing system.

The issue concludes with a contribution by Sandra, which like Ota et al.'s study deals with the processing of homophones, but which differs from the other contributions in its focus on written L1. Sandra conducted two experimental tasks and two corpus studies on homophone dominance in the spelling of regularly inflected verb forms. The results revealed a strong effect of homophone dominance in the spelling of Dutch imperative forms, which could not be reduced to an effect of recency (i.e., the effect was not reduced when an imperative whose pronunciation reflected the spelling preceded the target form). The corpus-based studies further showed that the effect can also be found at the sublexical level. Sandra argues that this finding can be explained in a connectionist processing tradition, but is hard to account for in a rule-based framework. 
Together, these articles provide a picture of how orthography and phonology are interrelated. We hope that this special issue will encourage researchers working on orthography and phonology to take into account the research findings from neighboring subdisciplines. Specifically, it is our hope that the issue will lead to a cross-fertilization between the domain of psycholinguistics and that of second language acquisition.

\section{References}

CHEUNG, H., CHEN, H.-C., LAI, C. Y., WONG, O. C., \& HILLS, M. (2001). The development of phonological awareness: Effects of spoken language experience and orthography. Cognition, 81, 227-241.

COOK, V., \& BASSETTI, V. (2005). Second language writing systems. Clevedon: Multilingual Matters.

ESCUDERO, P., HAYES-HARB, R., \& MITTERER, H. (2008). Novel second-language words and asymmetric lexical access. Journal of Phonetics, 36, 345-360.

ESCUDERO, P., \& SIMON, E. (in preparation). The effect of orthographic cues on L2 word learning: Spanish learners' acquisition of novel words containing Dutch vowel contrasts.

GOSWAMI, U., ZIEGLER, J. C., \& RICHARDSON, U. (2005). The effects of spelling consistency on phonological awareness: A comparison of English and German. Journal of Experimental Child Psychology, 92, 345-365.

NUNES, T., BRYANT, P., \& OLSSON, J. (2003). Learning morphological and phonological spelling rules: An intervention study. Scientific Studies of Reading, 7, 289-307.

PAN, N., \& CHEN, L. (2005). Phonological/phonemic awareness and reading: A crosslinguistic perspective. Journal of Multilingual Communication Disorders, 3, 145-152.

PATTAMADILOK, C., MORAIS, J., VENTURA, P., \& KOLINSKY, R. (2007). The locus of the orthographic consistency effect in auditory word recognition: Further evidence from French. Language \& Cognitive Processes, 22, 700-726.

PERRE, L., \& ZIEGLER, J. C. (2008). On-line activation of orthography in spoken word recognition. Brain Research, 1188, 132-138.

SIMON, E., CHAMBLESS, D., \& ALVES, U. (2010). Understanding the role of orthography in the acquisition of a non-native vowel contrast. Language Sciences, 32, 380-394.

TAFT, M. (2001). Processing of orthographic structure by adults of different reading ability. Language and Speech, 44, 351-376.

TYLER, M. D., \& BURNHAM, D. (2006). Orthographic influences on phoneme deletion response times. Quarterly Journal of Experimental Psychology, 59, 2010-2031.

WEBER, A., \& CUTLER, A. (2004). Lexical competition in non-native spoken-word recognition. Journal of Memory and Language, 50, 1-25.

ZIEGLER, J. C., \& FERRAND, L. (1998). Orthography shapes the perception of speech: The consistency effect in auditory word recognition. Psychonomic Bulletin \& Review, 5, 683-689.

ZIEGLER, J. C., PETROVA, A., \& FERRAND, L. (2008). Feedback consistency effects in visual and auditory word recognition: Where do we stand after more than a decade? Journal of Experimental Psychology: Learning, Memory, \& Cognition, 34, 643-661. 